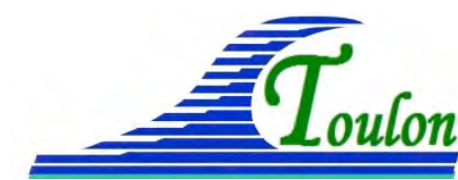
XIV èmes Journées Nationales Génie Côtier - Génie Civil
Toulon, 29 juin au $1^{\text {er }}$ juillet 2016

DOI:10.5150/jngcgc.2016.079 @ Editions Paralia CFL

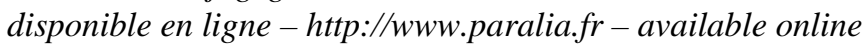

\title{
The Saint-Venant model for tsunami propagation simulation: Application to the 2011 Tohoku event
}

\author{
Kevin PONS ${ }^{1,2}$, Richard MARCER ${ }^{1}$, Frédéric GOLAY ${ }^{2}$
}

1. Principia S.A.S., Zone Athélia 1, 215 voie Ariane, 13705 La Ciotat cedex, France.

\{kevin.pons ; richard.marcer\}@principia.fr

2. Université de Toulon, IMATH, EA 2134, 83957 La Garde cedex, France.

\{kevin.pons ; frederic.golay\}@univ-tln.fr

\begin{abstract}
:
Beside a validation step of numerical models regarding academic tsunami test cases, one of the topic of the TANDEM project aims to qualify long distance propagation models on real tsunami events. In this context, the Saint-Venant model is used to simulate the 2011 Tohoku tsunami in Japan. The numerical resolution is based on a well-balanced finite volumes solver on unstructured mesh. The results are compared to available near and far shore in-situ data. The numerical accuracy is improved by the use of an adaptive mesh refinement method. The relevancy of a non-dispersive model for this event is then discussed.
\end{abstract}

Keywords: Tsunami, Propagation, Dispersion, Saint-Venant, Non-linear shallow water, Validation.

\section{Introduction}

The TANDEM project aims to improve knowledge on the tsunami risk on the French coasts. A first step of this project is dedicated to validation of CFD models on academic test cases of wave propagation and impact on structures; see for instance (PONS et al., 2015, MARCER et al., 2015; VIOLEAU et al., 2016; PONS et al., 2016). The second step of this project concerns the sensitivity of modelling parameters and the definition of uncertainties regarding simulations of tsunamis, from the source at large scale up to local coastal impacts. According to this methodology, the models are then evaluated on real tsunamis events within a third step of the project. In this context the present study shows a numerical modelling of the 2011 Tohoku tsunami on a large zone around the Japan allowing to evaluate the reliability of the model for simulation of the wave over very large scales.

The numerical soft used in this paper is the EOLENS code developed by Principia and IMATH (Institut de Mathématiques de Toulon).

The first part of the paper deals with a brief presentation of the Saint-Venant model and its application regarding tsunamis propagation. Then the finite volume solver and the adaptive mesh refinement method used are presented. Finally numerical simulations of the 2011 Tohoku tsunami are compared with some available in-situ data. 


\section{The Saint-Venant model for tsunami propagation}

Tsunami is generally referred to any impulse generated gravity wave. It can be generated by different kinds of sources. The most common tsunamis are a consequence of earthquake, landslide and volcanic explosion. Such events can displace very large volume of water from its equilibrium, resulting in gravity waves generation. Depending of the tsunami source, the order of magnitude of a tsunami wave length is about several tens kilometres. As this horizontal length is much larger than the water depth, vertically integrated model are generally used for tsunami propagation.

A quite simple model is the Saint-Venant one, often called the NLSW model (Non Linear Shallow Water), in which the waves are non-dispersive. When dispersive effects are important, the Boussinesq or the Green Naghdi model is more adapted.

When a tsunami come up close to the shore, the wave starts to compresses horizontally and grows vertically (shoaling phenomenon). For high shoaling effect, the wave can break down as nonlinear phenomena become dominant. Because of the unique vertical evaluation of the flow field in the Saint-Venant model, the wave can not break. However the wave may converge to a shock for which the characteristic velocity and the decreasing wave amplitude are quite well representative of a breaking wave (see for instance BONNETON, 2003). Therefore, the Saint-Venant model may be used to simulate the tsunami propagation in the whole ocean, from the generation up to the coast. But, as even smooth waves converge in a finite time to a shock wave, the wave shape may be poorly reproduced (especially for long distance propagation), inducing a prematurely loss of energy during wave propagation. This problem may be overcome using a dispersive model.

The two dimensional Saint-Venant system on a variable bathymetry is (with $\vec{U}=\left(\begin{array}{l}\bar{u} \\ \bar{v}\end{array}\right)$ ):

$\left\{\begin{array}{c}\frac{\partial h}{\partial t}+\operatorname{div}[h \vec{U}] \\ \frac{\partial h \vec{U}}{\partial t}+\operatorname{div}\left[h \vec{U} \otimes \vec{U}+\frac{g h^{2}}{2} \bar{I}\right]=-g h \nabla z\end{array}\right.$

with $h$ the water height, $\vec{U}$ the mean horizontal velocity vector, $g$ the gravitational constant and $z$ the sea bottom.

For $h>0$, the model is strictly hyperbolic. This property allows using very reliable numerical methods to solve it. They are presented in the next section.

\section{Finite Volume method on unstructured mesh}

The computational domain is split in cells or control volumes. Equation (1) without the source term is integrated on each cell using the Green formula (where $\vec{n}_{k / a}$ denotes the unit normal vector on the boundary $\partial C_{k / a}$ between cells $k$ and $a$ ) and integrating in time from $t^{n}$ to $t^{n+1}$. Noting $\vec{w}=\left(\begin{array}{c}h \\ h \bar{u} \\ h \bar{v}\end{array}\right)$, we have:

$\int_{t^{n}}^{t^{n+1}} \int_{C_{k}} \frac{\partial \vec{w}}{\partial t} d V d t+\int_{t^{n}}^{t^{n+1}} \int_{\partial C_{k / a}} f(t, \vec{w}) \cdot \vec{n}_{k / a} d S d t=0$ 


\section{XIV èmes Journées Nationales Génie Côtier - Génie Civil \\ Toulon, 29 juin au $1^{\text {er }}$ juillet 2016}

For first order space integration, all cells are approximated by their mean values. Thus:

$\vec{w}_{k}^{n} \cong \frac{1}{\left|C_{k}\right|} \int_{C_{k}} \vec{w}(t, x, y) d V$

Next fundamental aspect of finite volume methods concerns the right hand term approximation. Indeed, because time and space dependence of $f(t, \vec{w})$ are not exactly known, the exact integration can't be done. But, thanks to the hyperbolic property, information propagates with finite speed. Therefore it is reasonable to assume that the interface fluxes are not perturbed during a well-chosen time step and are only dependent to cells states on either side of their respective interfaces. It means:

$f(t, \vec{w}) \cdot \vec{n}_{k / a} \cong F\left(\vec{w}_{k}^{n}, \vec{w}_{a}^{n}, \vec{n}_{k / a}\right)$

The numerical flux $F$ is defined with the Godunov solver (ie. it is computed with the exact solution of the $1 \mathrm{D}$ Riemann problem at interfaces). Replacing the previous approximations (3) and (4) in the equation (2), we get:

$\left|C_{k}\right| \int_{t^{n}}^{t^{n+1}} \frac{\overrightarrow{\partial w}_{k}^{n}}{\partial t} d t+\Delta t \int_{\partial C_{k / a}} F\left(\vec{w}_{k}^{n}, \vec{w}_{a}^{n}, \vec{n}_{k / a}\right) d S \cong 0$

Then using the forward Euler scheme we have finally a fully-discrete finite volume scheme:

$\vec{w}_{k}^{n+1}-\vec{w}_{k}^{n}+\frac{\Delta t}{\left|C_{k}\right|} \sum_{a} F\left(\vec{w}_{k}^{n}, \vec{w}_{a}^{n}, \vec{n}_{k / a}\right) C_{k / a} \cong 0$

To ensure the scheme stability, the time step has to respect the CFL (Courant-FriedrichLevy) condition. To increase the accuracy, second order space and time integration can be used, see for instance ERSOY et al. (2013) and MARCHE (2005). For the source term treatment, the hydrostatic reconstruction of AUDUSSE et al. (2004) is used allowing a well-balanced scheme.

\section{Adaptive Mesh Refinement (AMR) method}

Solving accurately the Saint-Venant model, even if quite simple, still requires significant computational resources for large variety of scales problems (POPINET, 2011). As modelling the large scale propagation in the ocean with a fine resolution is unadapted it may be efficient to dynamically refine the mesh only in interesting areas, and then to improve the accuracy while keeping reasonable CPU time. In particular at specific locations, for instance along the coast, it may be necessary to refine the grid in order to model small-scale features of the bathymetry and onshore infrastructures.

In the AMR method the computational domain is divided in several blocks, each corresponding to the initial unstructured mesh composed of hexahedral cells. These blocks are in turn splitted in a Cartesian way. For each refined cells (or blocks), averaged values are projected on each sub-cell and fluxes are computed as simply as possible to avoid heavy computation. Then, in order to balance the CPU's load, the cells of each block are re-distributed in a fixed number of domains according to the CuthillMcKee numbering. The number of domain being fixed, each domain is loaded in a given MPI process. The re-numbering and re-meshing being expensive, the mesh is 


\section{Thème 7 - Risques côtiers}

finally kept constant on a time interval, called AMR time-step, given by the smallest block (rather by the smallest cell) and the maximum velocity. Details on the 3D BBAMR (Block-Based) are given in ALTAZIN et al. (2016) and GOLAY et al. (2015) for instance. An illustration is proposed in the figure below.

For the refinement threshold allowing to select where mesh refinement or coarsening is needed, the readers may refer to PONS \& ERSOY (2016) which details the method.

Domain 3

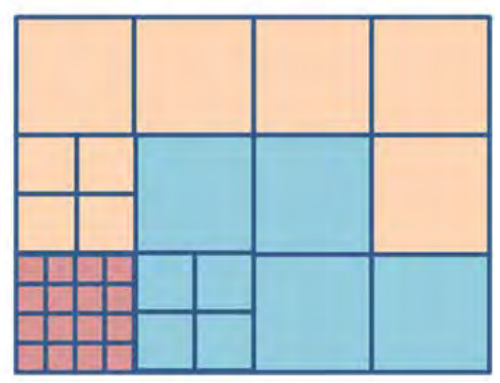

Domain 1 Domain 2

Figure 1. Example of non-structured and non-conforming BB-AMR mesh distributed on 3 domains.

\section{Application of the Saint-Venant model on the 2011 Japan tsunami}

The 11 March 2011 Tohoku-Oki event is exceptionally well documented. Indeed water level buoys and seismic sensors close to the epicentre are available allowing to quite well characterising the tsunami source. Furthermore, a lot of water level data on buoys close to the impacted cities (for instance Iwate, Miyagi and Fukushima) and in far field are also available. Therefore, this catastrophic event allows qualifying numerical models with a good accuracy.

There are more than twenty different sources available for this tsunami (TAPPIN et al., 2014). They are mainly referred to a slip on an earthquake fault but as proposed by GRILLI et al. (2013), an additional source (a submarine landslide) is also probable for this event.

The tsunami generation used in this paper is taken from SAKATE et al., (2013) who have considered a slip source alone and given good propagation results. The slip distribution is divided into 55 sub faults. Static sea bottom deformation is calculated by a rectangular fault model assuming an elastic half-space (OKADA, 1985). The horizontal displacement effects are also considered. Sakate showed the importance of horizontal contributions on the tsunami amplitude. For the inversion, the linear shallow water equations are numerically solved with a finite-difference method and are used as the Green's functions. Sakate also provides a multiple time window inversion improving again the result but for the sake of simplicity this last and more complex 


\section{XIV ${ }^{\text {èmes }}$ Journées Nationales Génie Côtier - Génie Civil \\ Toulon, 29 juin au $1^{\text {er }}$ juillet 2016}

tsunami source is not used in this paper meaning that the fault is assumed to be instantaneous.

As we do not attempt to solve accurately the coast run up, the bathymetry map used has been taken from (IOC, 2011) providing an accuracy of about 30 arc-second dataset (about 900 meters). The area solved is about 2,500km $\times 5,000 \mathrm{~km}$.

Two kinds of comparisons about water level data have been done in this paper, with buoys close to the epicentre on one hand and with buoys close to the coast on the other hand. Two simulations have been done, one using a fixed grid with a step size of $1.5 \mathrm{~km}$ and a second using an adaptive grid with varying step size from $0.7 \mathrm{~km}$ to $11.7 \mathrm{~km}$. For both simulations a second order time integration scheme (Rung-Kutta) have been used and the CFL have been set to 0.5 .

Figures 2 and 3 show the far field buoys (DART) and the nearshore buoys (GPS). The DART data have been taken from NOAA (2011). For the GPS buoys the data have been supplied by partners of the TANDEM project.

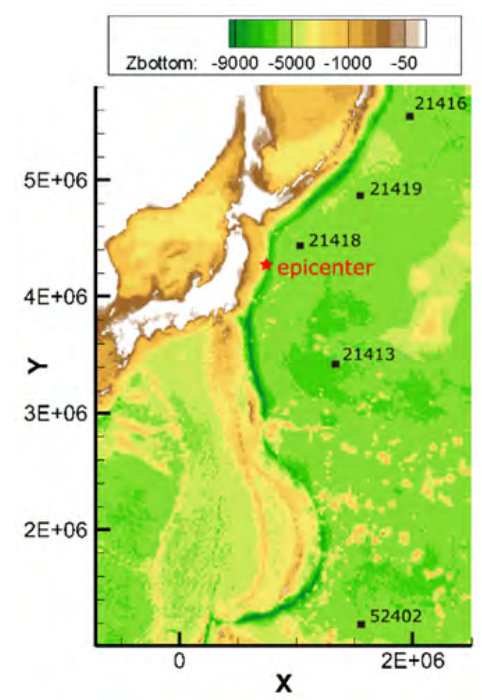

Figure 2. Area studied and DART buoys positions.

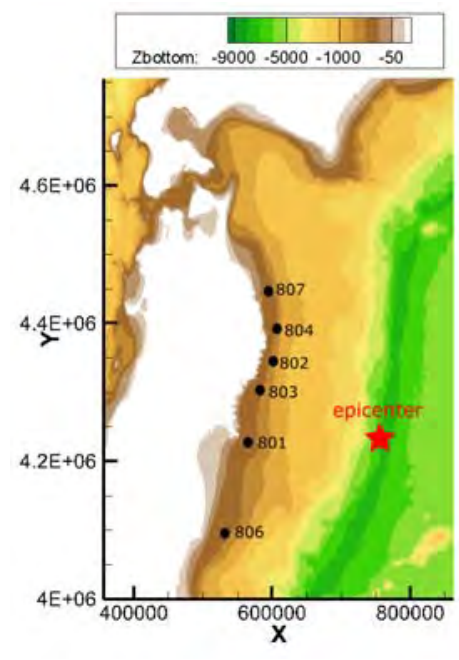

Figure 3. Nearshore GPS buoys positions.

\subsection{Far field comparisons}

Figure 4 shows wave elevation results of the two computations (uniform mesh in green and adaptive mesh in red) compared with offshore DART buoys (in black).

Globally the numerical results are quite good. The tsunami arrival is well predicted for the closest buoys of the epicentre (DART 21413, 21418, 21419, 21416) but a bit less accurate for the furthest one (DART 52402). The phase shift which is increased for the DART 52402 with respect to the DART 21413 seems to highlight dispersive effects, not accounted for with the model. However this time shift is very small so the dispersive effects appear to be negligible over the large distance computed here. These results are 
in line with LOVHOLT et al. (2012), KIRBY et al. (2013) and POPINET (2015). However, for again larger distance propagation, Kirby showed an increasing of dispersive effects. Also, depending of the propagation direction studied (here mainly the north and south direction), the importance of dispersive effects is not equitably distributed (see KIRBY et al. (2013) for a large distance propagation study in the east direction).

The wave amplitude is well reproduced for all buoys except the buoy DART 21418 for which the wave amplitude is underestimated. However adaptive mesh simulation shows a slight improvement of the results. It means that probably a mesh even more refined would improve again the results as it was shown for instance by POPINET (2012) who used a 3 time smaller grid than the adaptive computation presented here.
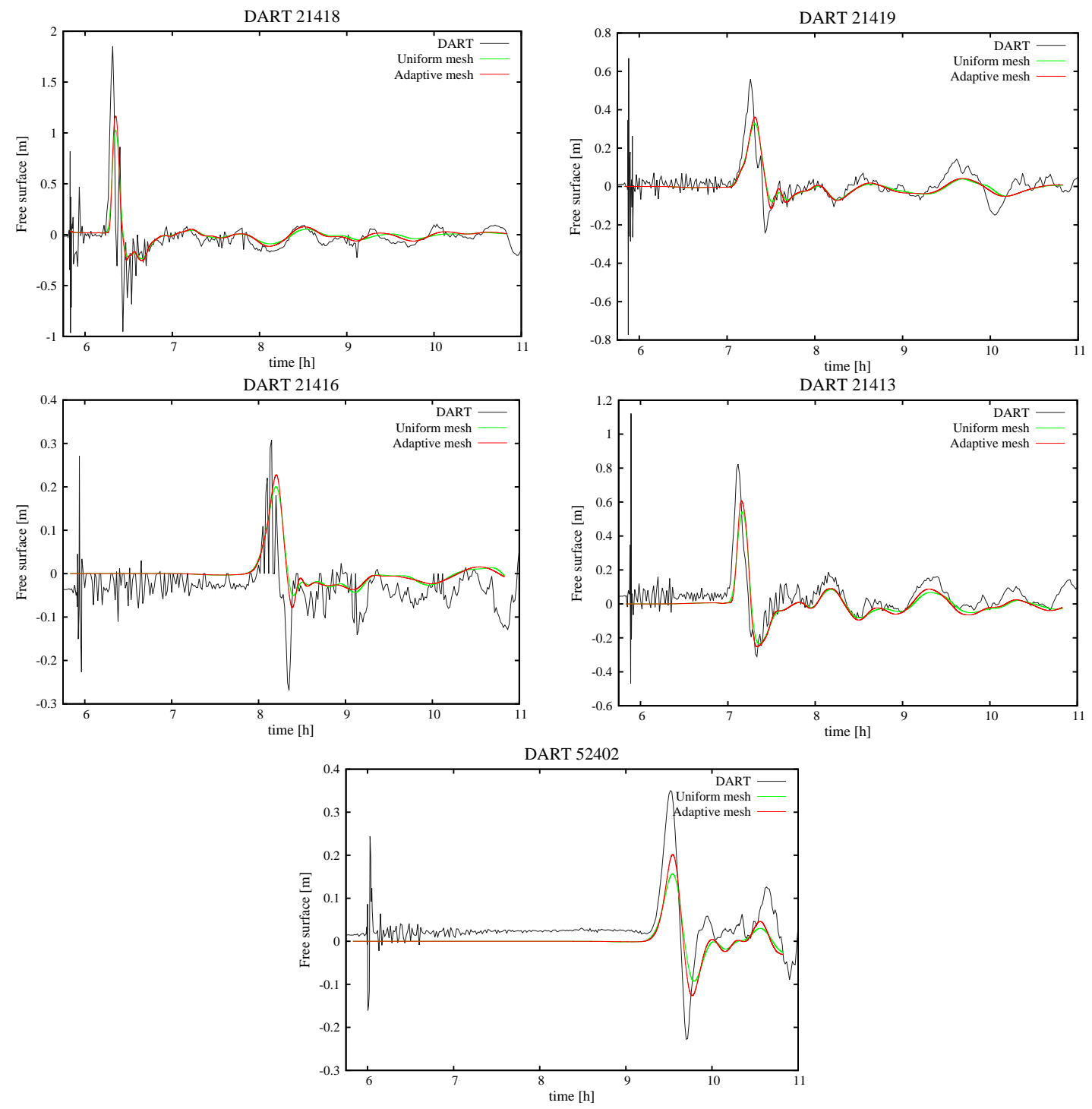

Figure 4. Comparisons of uniform and AMR simulations with DART buoys data 


\section{XIV ${ }^{\text {èmes }}$ Journées Nationales Génie Côtier - Génie Civil \\ Toulon, 29 juin au $1^{\text {er }}$ juillet 2016}

\subsection{Nearshore comparisons}

Figure 5 shows wave elevation results of the two computations (uniform mesh in green and adaptive mesh in red) compared with GPS buoys data (in black).

As for the DART buoys, the numerical results are satisfactory on the whole. GPS buoys 801 and 803 are well reproduced whereas GPS buoys 804, 807 and 802 are also quite well evaluated but the leading wave amplitude is underestimated for them.
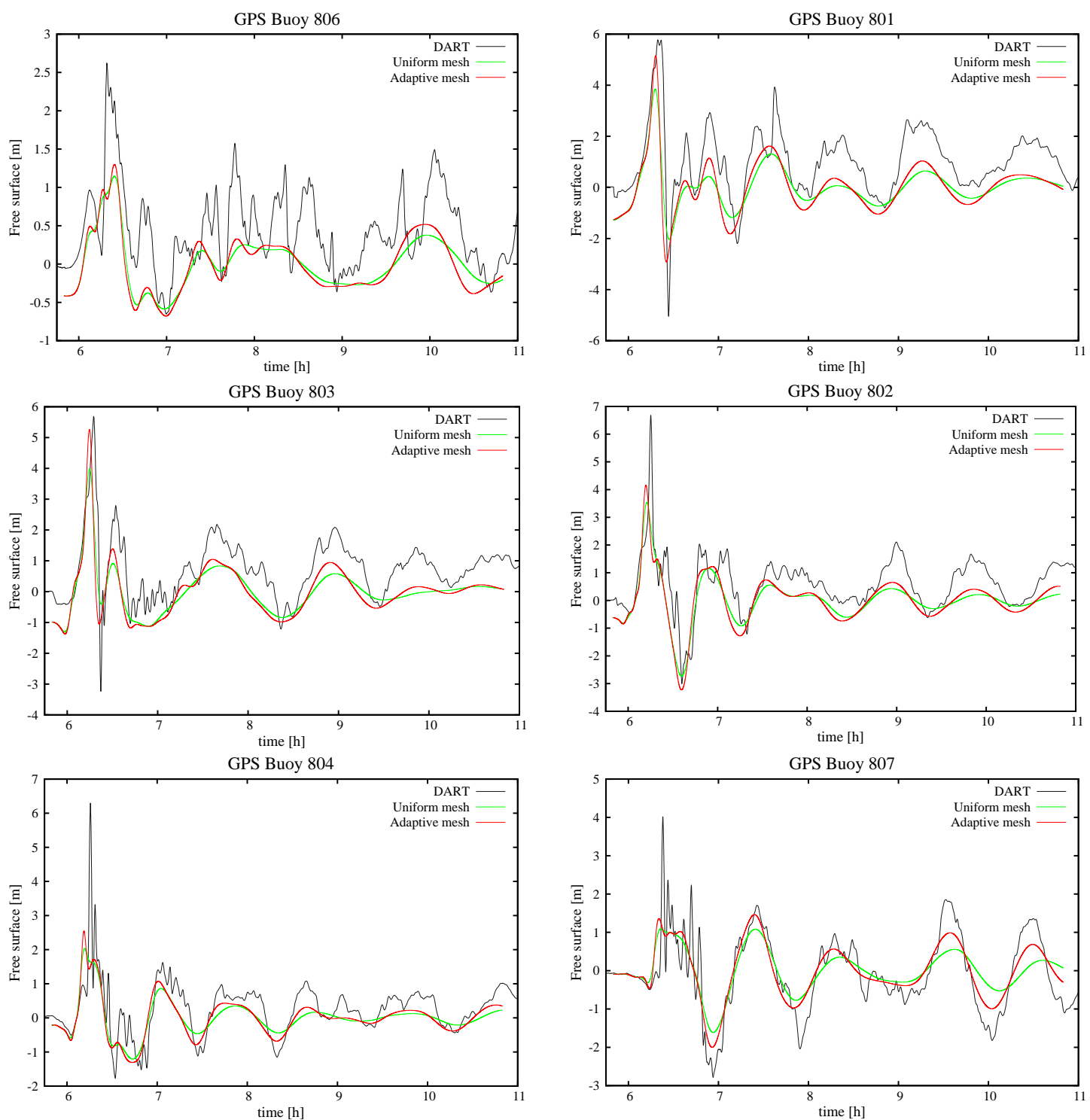

Figure 5. Comparisons of uniform and AMR simulations with GPS buoys data.

The poorer result concerns the GPS buoy 806 where a slight amplitude shift is observed. Because this shift appears right at the beginning of the simulation, it seems to highlight a weakness of the tsunami source used in the model. SAKATE et al. (2013) proposed 


\section{Thème 7 - Risques côtiers}

another more complex source with a time dependant inversion. Also, GRILLI et al. (2013) proposed an additional submarine landslide source for this event. These models should be considered to clearly conclude on this point. Another parameter possibly affecting the propagation is the lack of accuracy about the bathymetry resolution close to the shore. To finish, due to large bathymetry variations, the non-hydrostatic effects may have consequences on the wave propagation as shown by DUTYKH \& CLAMOND (2015) on an academic test case.

\section{Conclusions}

In this paper, the Tohuku tsunami in Japan is simulated with the Saint-Venant model using or not an adaptive mesh refinement method. On the whole this model allows obtaining quite good results but with differences of accuracy according to positions of the buoys.

For far coast buoys (DART), the numerical results are satisfactory for the near tsunami source comparisons. On the faraway buoy (DART 52402) quite small time decay is put into evidence showing small dispersive effects of the wave at this large scale and therefore justifying the pertinence of the Saint-Venant model on the area studied.

For near coast buoys (GPS), the numerical results are good. However wave elevations on the furthest buoys (GPS 804, 807 and 802) are less accurate. This can be attributed to the accuracy of the tsunami source model, to the bathymetry and meshing resolution or to the non-hydrostatic effects.

On the whole the adaptive mesh refinement method tends to improve the results without too much additional computational time. To go further in the accuracy of the model two focuses of work will be considered, the optimization of meshing discretization (associated with bathymetry) and the improvement of the tsunami source model.

\section{Aknowledgments}

This work has been done in the framework of the French national research project TANDEM (Tsunamis in the Atlantic and the English ChaNnel: Definition of the Effects through Numerical Modeling). This project is supported by the French government (Projets Investissement d'Avenir, agreement reference number ANR-11-RSNR-002301). The authors want to thank Rodrigo Pedreros and Sylvestre Le Roy from BRGM for their support on the tsunami source modelling and the bathymetry treatment.

\section{References}

ALTAZIN T., ERSOY M., GOLAY F., SOUS D., YUSCHENKO L., (2016). Numerical investigation of bb-amr scheme using entropy production as refinement criterion. Accepted in International Journal of Computational Fluid Dynamics. 


\section{XIV vèmes Journées Nationales Génie Côtier - Génie Civil \\ Toulon, 29 juin au $1^{\text {er }}$ juillet 2016}

AUDUSSE E., BOUCHUT F., BRISTEAU M.-O., KLEIN R., PERTHAME B. (2004). A fast and stable well-balanced scheme with hydrostatic reconstruction for shallow water flows. SIAM Journal on Scientific Computing, Vol. 25(6), pp 2050-2065. http://dx.doi.org/10.1137/S1064827503431090

BONNETON P. (2003). Dynamique non linéaire des vagues en zone de surf interne. Revue Française de Génie Civil, numéro spécial "Génie-Côtier", pp 1061-1076. http://dx.doi.org/10.1080/12795119.2003.9692534

DUTYKH D., CLAMOND D. (2015). Modified Shallow Water Equations for significantly varying bottoms. Submitted. Available on https://hal.archives-ouvertes.fr/hal-00675209v5 ERSOY M., GOLAY F., YUSHCHENKO L. (2013). Adaptive multiscale scheme based on numerical density of entropy production for conservation laws. Open Mathematics, Vol. 11(8), pp 1392-1415. http://dx.doi.org/10.2478/s11533-013-0252-6

GOLAY F., ERSOY M., YUSCHENKO L., SOUS D. (2015). Block-based adaptive mesh refinement scheme using numerical density of entropy production for threedimensional two-fluid flows. International Journal of Computational Fluid Dynamics, Vol. 29(1), pp 67-81. http://dx.doi.org/10.1080/10618562.2015.1012161

GRILLI S.T., HARRIS J.C., BAKHSH T.S.T., MASTERLARK T.L., KYRIAKOPOULOS C., KIRBY J.T., SHI F. (2013). Numerical Simulation of the 2011 Tohoku Tsunami Based on a New Transient FEM Co-seismic Source: Comparison to Far- and Near-Field Observations. Pure Appl. Geophys. Vol. 170, pp 1333-1359. http://dx.doi.org/10.1007/s00024-012-0528-y

IOC (2011). IOC: General Bathymetric Chart of the Oceans. Available on: http://www.gebco.net/data_and_products/gridded_bathymetry_data

KIRBY J. T., SHI J., TEHRANIRAD B., HARRIS J. C., GRILLI S. T. (2013). Dispersive tsunami waves in the ocean: Model equations and sensitivity to dispersion and Coriolis effects. Ocean Modelling, Vol. 62, pp 39-55. http://dx.doi.org/10.1016/j.ocemod.2012.11.009

LOVHOLT F., KAISER G., GLIMSDAL S., SCHEELE L., HARBITZ C. B., PEDERSEN G. (2012). Modeling propagation and inundation of the 11 March 2011 Tohoku tsunami. Nat. Hazards Earth Syst. Sci., Vol. 12, pp 1017-1028. http://dx.doi.org/10.5194/nhess-12-1017-2012

MARCER R., PONS K., JOURNEAU C. (2015). Validation of CFD models for tsunami simulation. TANDEM Project. Revue Paralia, Vol. 8 pp n04.1-n04.06. http://dx.doi.org/10.5150/revue-paralia.2015.n04

MARCHE F. (2005). Theorical and Numerical Study Of Shallow Water Models. Applications to Nearshore Hydrodynamics. PhD., Bordeaux University, France.

NOAA (2011). NOAA: National Data Buoy Center - DART. URL: http://www.ndbc.noaa.gov/dart.shtml

OKADA Y. (1985). Surface deformation dee to shear and tensile faults in a half-space. Bulletin of the Seismological Society of America, Vol. 75(4), pp 1135-1154. 
PONS K., JOURNEAU C., MARCER R., GOLAY F. (2015). Calculs CFD de propagation et d'impact de vague en zone côtière. Projet TANDEM. $33^{\text {èmes }}$ Rencontres de l'AUGC, ISABTP/UPPA, Anglet, France.

PONS K., ERSOY M., (2016). Adaptive mesh refinement method. Part 1: Automatic thresholding based on a distribution function. Submitted.

PONS K., ERSOY M., GOLAY F., MARCER R. (2016). Adaptive mesh refinement method. Part 2: Application to tsunami propagation. Submitted.

POPINET S. (2011). Quadtree-adaptive tsunami modelling. Ocean Dynamics Vol. 61(9), pp 1261-1285. http://dx.doi.org/10.1007/s10236-011-0438-z

POPINET S. (2012). Adaptive modelling of long-distance wave propagation and finescale flooding during the Tohoku tsunami. Natural Hazards and Earth System Sciences Vol. 12(4), pp 1213-1227. http://dx.doi.org/10.5194/nhess-12-1213-2012

POPINET S. (2015). A quadtree-adaptive multigrid solver for the Serre-Green-Naghdi equations. Journal of Computational Physics, Vol. 302, pp 336-358. http://dx.doi.org/10.1016/j.jcp.2015.09.009

SAKATE K., FUJII Y., HARADA T., NAMEGAYA Y. (2013). Time and space distribution of coseismic slip of the 2011 Tohoku earthquake as inferred from tsunami waveform data. Bulletin of the Seismological Society of America, Vol. 103(2B), pp 1473-1492. http://dx.doi.org/10.1785/0120120122

TAPPIN D. R., GRILLI S. T., HARRIS J. C., GELLER R. J., MASTERLARK T., KIRBY J. T., SHI F., Ma G., THINGBAIJAM K. K. S., MAI P. M. (2014). Did a submarine landslide contribute to the 2011 Tohoku tsunami? Marine Geology, Vol. 357, pp 344-361. http://dx.doi.org/10.1016/j.margeo.2014.09.043

VIOLEAU D., et al. (2016), A database validation cases for tsunami numerical modelling. $4^{\text {th }}$ IAHR Europ Congress, Belgium. Accepted. 